\title{
InSAR data analysis at Kamchatka during 2016
}

\author{
Igor Larionov ${ }^{1, \star}$ and Andrey Perezhogin ${ }^{1,2, \star \star}$ \\ ${ }^{1}$ Institute of Cosmophysical Research and Radio Wave Propagation FEB RAS (IKIR FEB RAS), \\ 684034, Mirnaya str., 7, Paratunka, Elizovskiy district, Kamchatka, Russia \\ ${ }^{2}$ Vitus Bering Kamchatka State University, \\ 683032, Pogranichnaya str.4, Petropavlovsk-Kamchatsky, Russia
}

\begin{abstract}
Geophysical monitoring in seismically active areas depends on geodeformation processes in the earth's crust. Observations of earth's crust strain-stress using gps-measurements, laser interferometers give only an opportunity to analyze the dynamics in time without the possibility of extrapolation to adjacent areas. In this regard, it is useful to apply a radar interferometry technology to measure the displacements of the earth's surface. The report includes the results of processing the radar data of the Sentinel-1A satellite. Several qualitative interferometric pairs were obtained during the period from June to October 2016. A high coherence coefficient is observed in open areas in the vicinity of volcanic structures and adjacent territories, as well as on the west coast of Kamchatka, where there is no high vegetation. The main factor that significantly reduces the coherence of images is the forest cover. Possibility of estimating the surface displacement at regions with a high coherence coefficient is discussed.

Keywords: InSAR, strain-stress, Sentinel-1A
\end{abstract}

\section{Introduction}

There are several instrumental geophysical stations in Kamchatka region. The aim is a monitoring of geophysical variations of seismic and volcano's activity and its influence on geophysical processes. The main impact on geophysical fields is a stress-strain state of the earth's crust [1-4]. In this paper we analyze Sentinel-1A satellite SAR data in order to compare modeling results with InSAR data. We investigate pairs of radar data in Southern Kamchatka because of the location of varios geophysical stations near Petropavlovsk-Kamchatsky.

\section{InSAR data and instruments}

InSAR is an effective technique to investigate strain-stress of Earth's surface due to subduction zone displacement. There are several applications in monitoring of seismic and volcano activities. For example, InSAR is used to determine stress of the San Andreas fault in California [5]. Uzon caldera strain-stress at Kamchatka was observed by satellite [6].

\footnotetext{
$\star^{\star}$ e-mail: igor@ikir.ru

$\star \star$ e-mail: d72156@gmail.com
} 


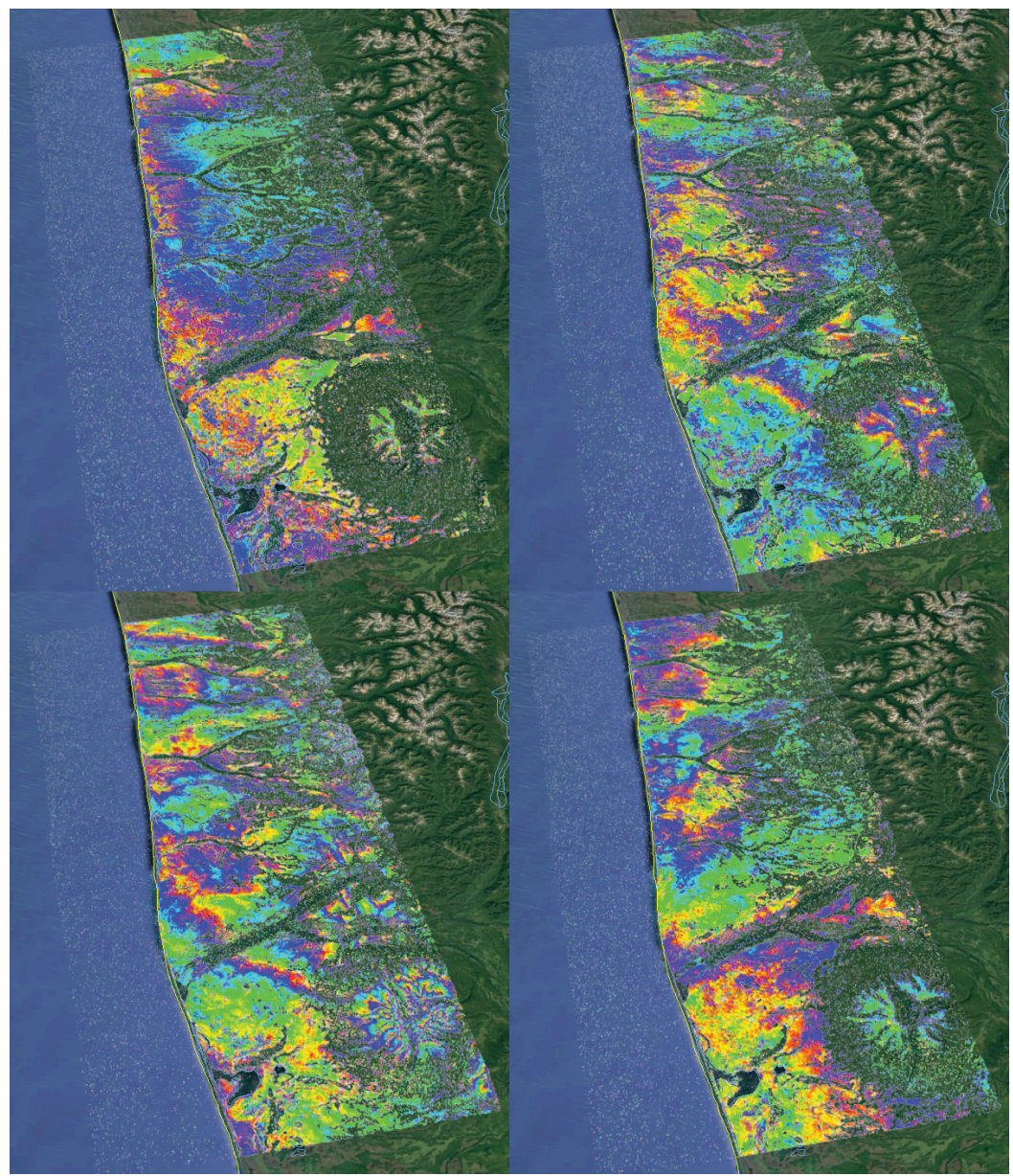

Figure 1. InSAR data for pair 2016.06.28-07.22 (upper left), 2016.07.22-08.15 (upper right), 2016.08.15-09.08 (bottom left), 2016.09.08-10.02 (bottom right)

In paper we consider region of Southern part of Kamchatka. We use Copernicus Open Access Hub for IW data of Sentinel-1A. Processing of Sentinel-1A data was performed using GMTSAR software [7].

During period from January 2016 to December 2016 we find out a high coherence only in summer and autumn months. Difference of phases is represented at fig. 2. There are many continuous regions with stable phase differences. Indeed this territory has no forests. But territory near PetropavlovskKamchatsky is surrounded by forests. So we have a high coherence only at mountains and rocks.

There is no high coherence for winter period data because of unregulated character of snow surface. We analyze images in January and February 2016. If we discuss spring period there are the same problems with coherence. Most suitable periods are from June to October when the ground is free of snow.

So for investigation of strain-stress at Kamchatka we need a representative collection of InSAR data for summer and autumn periods. 


\section{Conclusion}

We get InSAR pairs of data for analysis of a stress-strain field at Kamchatka region. There is sufficiently high coherence for pairs of images during summer period near volcanoes without forests.

\section{References}

[1] A. Alekseev, A. Belonosov, B. Petrenko, Problems in the dynamics of the lithosphere and seismicity. Computational Seismology pp. 81-97 (2001)

[2] A. Perezhogin, B. Shevtsov, Computational technologies 14 (2009)

[3] M. Bobrova, A. Perezhogin, Herald of KRAUNTS. Physics and mathematics 2 (2011)

[4] V. Saltykov, Y. Kugaenko, Pacific Geology 31, 96 (2012)

[5] Y. Fialko, Nature 441, 968 (2006)

[6] P. Lundgren, Z. Lu, Geophysical Research Letters 33 (2006)

[7] D. Sandwell, R. Mellors, X. Tong, M. Wei, P. Wessel, Eos, Transactions American Geophysical Union 92, 234 (2011) 